BMJ Paediatrics Open

\title{
Sex differences in congenital heart disease in Down syndrome: study data from medical records and questionnaires in a region of Japan
}

Takako Takano, ${ }^{\oplus 1}$ Michio Akagi, ${ }^{2}$ Haruyoshi Takaki, ${ }^{3}$ Ryo Inuzuka, ${ }^{4}$ Yoshitsugu Nogimori, ${ }^{5}$ Hiroshi Ono, ${ }^{6}$ Masahide Kaneko, ${ }^{7}$ Norifumi Hagiwara ${ }^{8}$

To cite: Takano T, Akagi M, Takaki H, et al. Sex differences in congenital heart disease in Down syndrome: study data from medical records and questionnaires in a region of Japan. BMJ Paediatrics Open 2019;3:e000414. doi:10.1136/ bmjpo-2018-000414

- Additional material is published online only. To view, please visit the journal online (http://dx.doi.org/10.1136/ bmjpo-2018-000414).

Received 6 December 2018 Accepted 1 April 2019
Check for updates

(C) Author(s) (or their employer(s)) 2019. Re-use permitted under CC BY-NC. No commercial re-use. See rights and permissions. Published by BMJ

For numbered affiliations see end of article.

Correspondence to Dr Takako Takano; takano@ tokyo-kasei.ac.jp

\section{ABSTRACT}

Reports indicate lower Down syndrome (DS) survival among females than among males in Australia, contrasting with female longevity in the general population. Using data on 1310 people with DS (626 females and 684 males) in Japan from five hospitals' medical records and questionnaires completed by parents of people with DS, we investigated sex differences in congenital heart disease (CHD), which may be related to mortality. The CHD rate was significantly higher for females $(354,57 \%)$ than for males $(338,49 \% ; p=0.010)$. Significantly more females $(199,32 \%)$ than males $(175,26 \%)$ underwent surgery for CHD $(p=0.018)$.

\section{INTRODUCTION}

Life expectancy for people with Down syndrome (DS) has increased in Australia, ${ }^{1}$ Japan $^{2}$ and other advanced countries. In Japan, improvements in early survival have been attributed to surgical intervention for congenital heart disease (CHD) ${ }^{3}$ In Australia, in contrast to female longevity in the general population, males with DS were found to have significantly longer life expectancies, compared with their female counterparts. ${ }^{4}$ The shorter life expectancy of these females may be attributed to their higher prevalence of CHD. This study aimed to clarify sex differences in the prevalence and severity of CHD among Japanese people with DS.

\section{METHODS}

We used data from medical records from five hospitals in Tokyo and two questionnaires completed by parents of people with DS in Tokyo and Shizuoka prefectures (online supplementary file 1). People with DS were not directly involved in the design of this study. Small (diameter $<6 \mathrm{~mm}$ ) fossa ovalis defects were excluded from the diagnosis of atrial septal defect (ASD). Arterial ducts closed before 1 month of age were excluded from the diagnosis of patent ductus arteriosus (PDA). Questionnaires were mailed to parents of people with DS; completing and returning the questionnaire was considered to indicate consent to participate. Statistical analyses were performed using SPSS V.21.

\section{RESULTS}

In total, there were 1310 subjects with DS (626 females and 684 males; sex ratio=1.09). The prevalence of CHD was significantly higher among females $(354,57 \%)$ than among males (338, 49\%; $\chi^{2}$ test: $\left.\mathrm{p}=0.010\right)$. Moreover, significantly more females $(199,32 \%)$ than males $(175,26 \%)$ underwent cardiac surgery $\left(\chi^{2}\right.$ test: $\mathrm{p}=0.018$; table 1$)$. The main CHD lesions (in order of prevalence) were ventricular septal defect (VSD), ASD, atrio-VSD (AVSD), PDA and tetralogy of Fallot (TOF; table 2). The prevalence of CHD with PDA was significantly higher in females $(115,18 \%)$ than in males $(87,13 \% ; p=0.005)$, whereas the prevalence of CHD without PDA was almost equal in females $(239,38 \%)$ and males $(251,37 \%$.)

Table 1 Congenital heart disease (CHD) and operations among people with Down syndrome by sex

\begin{tabular}{lcccc}
\hline & \multicolumn{2}{l}{ CHD (+) } & & \\
\cline { 2 - 3 } Sex & $\begin{array}{l}\text { Operation } \\
(+)\end{array}$ & $\begin{array}{l}\text { Operation } \\
(-)\end{array}$ & $\begin{array}{l}\text { CHD } \\
(-)\end{array}$ & Total \\
\hline Female & 199 & 155 & 272 & 626 \\
& $32 \%$ & $25 \%$ & $43 \%$ & $100 \%$ \\
Male & 175 & 163 & 346 & 684 \\
& $26 \%$ & $24 \%$ & $51 \%$ & $100 \%$ \\
Total & 374 & 318 & 618 & 1310 \\
& $29 \%$ & $24 \%$ & $47 \%$ & $100 \%$ \\
\hline
\end{tabular}

$\chi^{2}=8.05, \mathrm{df}=2, \mathrm{p}=0.018$.

Odds: female versus male with CHD $(95 \% \mathrm{Cl}) 1.33$ (1.07 to 1.66$)$. Odds: female versus male with CHD operation $(95 \% \mathrm{Cl}) 1.36(1.07$ to 1.72$)$. 
Table 2 Main congenital heart disease (CHD) lesion among people with Down syndrome by sex

\begin{tabular}{|c|c|c|c|c|c|c|}
\hline \multirow{3}{*}{$\begin{array}{l}\text { Main lesion } \\
\text { of CHD }\end{array}$} & \multicolumn{4}{|l|}{ Sex } & \multirow{2}{*}{\multicolumn{2}{|c|}{ Total }} \\
\hline & \multicolumn{2}{|l|}{ Female } & \multicolumn{2}{|l|}{ Male } & & \\
\hline & Number & Per cent & Number & Per cent & Number & Per cent \\
\hline VSD & 142 & 40.1 & 131 & 38.8 & 273 & 39.5 \\
\hline ASD & 75 & 21.2 & 70 & 20.7 & 145 & 21.0 \\
\hline AVSD & 55 & 15.5 & 47 & 13.9 & 102 & 14.7 \\
\hline PDA & 48 & 13.6 & 40 & 11.8 & 88 & 12.7 \\
\hline TOF & 23 & 6.5 & 30 & 8.9 & 53 & 7.7 \\
\hline PS & 1 & 0.3 & 5 & 1.5 & 6 & 0.9 \\
\hline DORV & & 0.0 & 3 & 0.9 & 3 & 0.4 \\
\hline Ebstein & 1 & 0.3 & 1 & 0.3 & 2 & 0.3 \\
\hline$A R$ & 1 & 0.3 & & 0.0 & 1 & 0.1 \\
\hline CoA & & 0.0 & 1 & 0.3 & 1 & 0.1 \\
\hline MR & 1 & 0.3 & & 0.0 & 1 & 0.1 \\
\hline TA & & 0.0 & 1 & 0.3 & 1 & 0.1 \\
\hline TR & & 0.0 & 1 & 0.3 & 1 & 0.1 \\
\hline Unknown & 7 & 2.0 & 8 & 2.4 & 15 & 2.1 \\
\hline Total & 354 & 100.0 & 338 & 100.0 & 692 & 100.0 \\
\hline
\end{tabular}

$\mathrm{AR}$, aortic regurgitation; ASD, atrial septal defect; AVSD, atrioventricular septal defect; CoA, coarctation of aorta; DORV, double outlet right ventricle; Ebstein, Ebstein's anomaly; MR, mitral regurgitation; PDA, patent ductus arteriosus; PS, pulmonary stenosis; TA, tricuspid atresia; TOF, tetralogy of Fallot; TR, tricuspid regurgitation; VSD, ventricular septal defect.

Among subjects born before 1979 (female: 34, 43.6\%; male: $10,18.5 \%$ ), in the 1980 s (female: $63,51.2 \%$; male: $46,37.7 \%$ ) or in the 1990 s (female: $74,59.7 \%$; male: $85,47.5 \%$ ), more females than males had CHD, but we found no significant sex difference in CHD prevalence for subjects born in 2000 or later (female: 183, 60.8\%; male: $196,59.8 \%$ ).

\section{DISCUSSION}

In our study, females with DS had a significantly higher prevalence of CHD than did males with DS, as has previously been reported in the $\mathrm{USA}^{5}$ and Europe. ${ }^{6}$ Higher prevalence and greater severity of CHD in females may contribute to poor prognoses. We found that the most common cardiac anomalies (main lesions) were VSD, ASD, AVSD, PDA and TOF, which together accounted for 95.5\% of all CHD cases. Likewise, a European network of population-based registers for the epidemiological surveillance of congenital anomalies study ${ }^{6}$ found that these five anomalies accounted for more than $99 \%$ of cardiac anomaly cases in people with DS. Among people with DS born before 1979, in the1980s or 1990s, we found that significantly more female than male subjects had CHD, but we found no significant sex difference for subjects born in 2000 or later. Many factors seem to have contributed to this change, including the improvement of diagnostic techniques, such as echocardiographic examination, and improvements in heart surgery. This shift may be attributed to a great increase in the diagnosis of less severe CHD for both sexes.

\section{Author affiliations}

${ }^{1}$ Department of Child Health, Tokyo Kasei University, Itabashi-ku, Japan

${ }^{2}$ Department of Medical Education, Kyorin University, Mitaka, Japan

${ }^{3}$ Department of Nursing, Tokyo Healthcare University, Meguro-ku, Japan

${ }^{4}$ Department of Pediatrics, University of Tokyo, Bunkyo-ku, Japan

${ }^{5}$ Department of Cardiovascular Medicine, Kanagawa Childrens Medical Center, Yokohama, Japan

${ }^{6}$ Division of Cardiology, National Center for Child Health and Development, Setagaya-ku, Japan

${ }^{7}$ Department of Pediatrics, Kanto Central Hospital of the Mutual Aid Association of Public School Teachers, Setagaya-ku, Japan

${ }^{8}$ Department of Pediatrics, Teikyo University, Itabashi-ku, Japan

Contributors TT designed the study, participated in the interpretation of the results and drafted the initial manuscript. MA participated in data collection and interpretation of the results. HT participated in data analysis and interpretation of the results. RI, YN, HO, MK and NH participated in data collection. All authors approved the final manuscript for submission.

Funding This work was supported by JSPS KAKENHI, grant number 23500893 , Japan.

Competing interests None declared.

Patient consent for publication Not Required

Ethics approval The study has received ethical approval from Tokyo Kasei University Ethics Committee, Kyorin University Ethics Committee, Teikyo University Ethics Committee, University of Tokyo Ethics Committee and National Center for Child Health and Development Ethics Committee.

Provenance and peer review Not commissioned; externally peer reviewed.

Open access This is an open access article distributed in accordance with the Creative Commons Attribution Non Commercial (CC BY-NC 4.0) license, which permits others to distribute, remix, adapt, build upon this work non-commercially, 
and license their derivative works on different terms, provided the original work is properly cited, appropriate credit is given, any changes made indicated, and the use is non-commercial. See: http://creativecommons.org/licenses/by-nc/4.0/.

\section{REFERENCES}

1. Glasson EJ, Sullivan SG, Hussain R, et al. The changing survival profile of people with Down's syndrome: implications for genetic counselling. Clin Genet 2002;62:390-3.

2. Masaki M, Higurashi M, lijima K, et al. Mortality and survival for Down syndrome in Japan. Am J Hum Genet 1981;33:629-39.
3. Hijii T, Fukushige J, Igarashi $\mathrm{H}$, et al. Life expectancy and social adaptation in individuals with Down syndrome with and without surgery for congenital heart disease. Clin Pediatr 1997;36:327-32.

4. Glasson EJ, Sullivan SG, Hussain R, et al. Comparative survival advantage of males with Down syndrome. Am J Hum Biol 2003;15:192-5.

5. Freeman SB, Bean LH, Allen EG, et al. Ethnicity, sex, and the incidence of congenital heart defects: a report from the National Down syndrome project. Genet Med 2008;10:173-80.

6. Morris JK, Garne E, Wellesley D, et al. Major congenital anomalies in babies born with Down syndrome: a EUROCAT population-based registry study. Am J Med Genet A 2014;164:2979-86. 